\title{
What Predicts Intergenerational Change in Anthropometry?
}

\author{
TIM J COLE \\ From the Population, Policy and Practice Programme, UCL Great Ormond Street Institute of Child Health, London, UK. \\ tim.cole@ucl.ac.uk
}

I $\mathrm{t}$ is a truth universally acknowledged, that children now are taller, heavier and fatter than their parents and grandparents were. Trends in adult height over the past 100 years have recently been documented in detail by the NCD Risk Factor Collaboration, comparing mean adult height by sex in 200 countries between 1896 and 1996 [1]. Some countries have seen height increase by up to $20 \mathrm{~cm}$. In addition, the pace of growth in childhood has accelerated, so that adult height is now reached at an earlier age. This has the effect of inflating the apparent increase in height during childhood, as children of a particular age are both taller and more advanced in developmental age [2]. Weight has also been increasing in line with height; but over the past half-century, it has outstripped height, and this has led to the secular trend of rising body mass index (BMI) and the public health concerns of increasing obesity.

Documenting these secular trends in child growth usually involves comparing anthropometry in crosssectional studies at different times; for example national surveys carried out every 10 or 15 years $[3,4]$. It is unusual to be able to make a direct comparison of the growth of children with their parents.

The article by Sinha, et al. [5] in this issue of Indian Pediatrics uses an interesting and unusual intergenerational study design to do just that - the growth patterns of children born around 1970 and recruited to the New Delhi Birth Cohort were compared with those of their own children as measured more recently. The comparisons focussed on the age groups $0-5$ and 5-10 years, where the outcomes were the intergenerational $\mathrm{Z}$-score changes in height, weight and BMI, adjusted for age and sex. The findings were striking - over the follow-up period, the children increased in height by a whole standard deviation, corresponding to $3.9 \mathrm{~cm}$ in the younger children and 6.4 $\mathrm{cm}$ in the older. Weight increased similarly, by 1.3 and 5.4 $\mathrm{kg}$ in the two age groups; while BMI changed only in the older children, by $1.9 \mathrm{~kg} / \mathrm{m}^{2}$, and in the $0-5$ year group it remained the same. The authors concluded that children tend to "grow up" before they "grow out."

This is one surprise, that the younger children were not fatter than their parents were at the same age, despite the steep rise in obesity prevalence that has occurred over the period. But the intergenerational study design also provided other interesting insights, some of them counterintuitive: the increases were greater for smaller and older parents, with poorer sanitation and higher education, and for older children. It is instructive to consider each of these associations in turn, and to explore their relevance to health policy. By far the strongest association was with parental size - the secular increase was appreciably greater for shorter parents. The authors provide three potential explanations for this: "statistical regression to the mean, narrowing of socio-economic inequalities and greater biological response among deprived strata", and they are optimistic that it represents a reduction in height inequity.

However, they are perhaps over-optimistic, in that the most likely explanation is the first of the three, regression to the mean, which is a statistical not a social or biological construct. It states simply that extreme measurements (e.g. height) are on average less extreme on remeasurement; so shorter parents tend to produce somewhat less short children, and vice versa for taller parents and children. It was first described by Francis Galton, working in the same context as here, with the heights of parents and children [6]. As a statistical phenomenon, regression to the mean is substantial and ever-present; so it tends to dwarf any other factors that may be operating.

The next strongest association the authors found was with parental age; the children of older parents tended to be relatively taller. The authors speculate that the parents being older meant they were exposed longer to improved living conditions, and passed this on to their children. However, there is another more likely explanation; the parents were all born around 1970, so if they were older when their children were born, the children must have been born later and hence experienced more of the underlying secular trend. In this sense, parental age is simply a measure of passing time, and the child's year of birth would have been similarly predictive.

The child's age was another important predictor of secular change, which was appreciably greater in the older 
age group. The authors view this as a proxy for exposure duration, but again it is more likely to be structural, reflecting the advanced developmental age of the children compared to their parents; so they reach milestones relatively earlier than their parents and hence appear taller. This effect increases with age until puberty and then disappears once adult height is reached [7]; so one would expect it to be greater for age 5-10y than age 0-5 y.

The secular change in developmental age may also explain why BMI did not increase in the 0-5 year group. The BMI curve typically rises steeply in infancy, peaks just before 1 year, then falls until adiposity rebound at age 4-5 y when it rises again [8]. The advance in developmental age shifts this pattern to the left, with both the age at BMI peak and the age at adiposity rebound getting earlier $[9,10]$, independently of any secular increase in BMI. Because of its shape, the age-shifted curve is slightly lower than the original curve at some ages (Fig. 1), and this generates an apparent fall in BMI that partially compensates for the secular BMI rise. So, in this sense the authors are right that children tend to "grow up" before they "grow out."

The WASH (Water, Sanitation and Hygiene) score, was the one socio-economic factor to have a measurable effect on the secular change in height, weight and BMI. It presumably means that the children brought up in better conditions than their parents grew better as a result. Weight

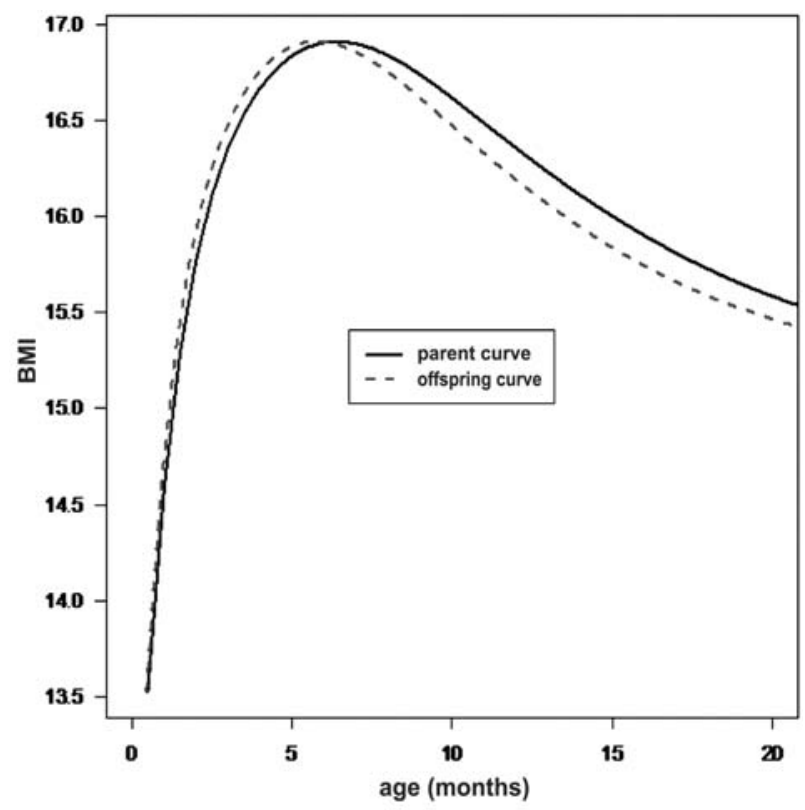

BMI from the WHO growth standard. The age scale for the offspring curve is shrunk by $10 \%$ compared to the parent curve.

FIG. 1 The effect of advanced developmental age on the BMI curve in early life, based on median. and BMI were also relatively greater in children whose parents were more educated; this though looks more like greater obesity than improved growth, as there was no associated height effect.

In summary, the study confirms intergenerational increases in height, weight and BMI, and identifies several factors that predict them. However, most of the factors reflect either statistical or biological associations that may not be very relevant to policy. In terms of policy relevance, only sanitation in the parent cohort impacted significantly on the secular height trend, suggesting that improved sanitation is a worthwhile policy goal. Sanitation in the child cohort did not show an effect, but this may be because it has improved materially in 30 years, making its impact harder to detect.

Funding: None; Competing interest: None stated.

\section{REFERENCES}

1. NCD Risk Factor Collaboration. A century of trends in adult human height. Elife. 2016. Jul 26;5. pii: e13410. doi: 10.7554/eLife. 13410.

2. Ong KK, Ahmed ML, Dunger DB. Lessons from large population studies on timing and tempo of puberty (secular trends and relation to body size): The European trend. Mol Cell Endocrinol. 2006;254:8-12.

3. Fredriks AM, van Buuren S, Burgmeijer RJ, Meulmeester JF, Beuker RJ, Brugman E, et al. Continuing positive secular growth change in The Netherlands 1955-1997. Pediatr Res. 2000;47:316-23.

4. Kim JY, Oh IH, Lee EY, Choi KS, Choe BK, Yoon TY, et al. Anthropometric changes in children and adolescents from 1965 to 2005 in Korea. Am J Phys Anthropol. 2008;136:230-6.

5. Sinha S, Aggarwal AR, Osmond C, Fall CHD, Bhargava $\mathrm{SK}$, Sachdev HS. Intergenerational change in anthropometric indices and their predictors among children in New Delhi Birth Cohort. Indian Pediatr. 2017;54:185-92.

6. Galton F. Regression towards mediocrity in hereditary stature. J R Anthropol Inst. 1886;15:246-63.

7. Cole TJ. Secular trends in growth. Proc Nutr Soc. 2000;59:317-24.

8. Rolland-Cachera MF, Deheeger M, Bellisle F, Sempé M, Guilloud-Bataille M, Patois E. Adiposity rebound in children: A simple indicator for predicting obesity. Am J Clin Nutr. 1984;39:129-35.

9. Johnson W, Choh AC, Lee M, Towne B, Czerwinski SA, Demerath EW. Characterization of the infant BMI peak: Sex differences, birth year cohort effects, association with concurrent adiposity, and heritability. Am J Hum Biol. 2013;25:378-88.

10. Doi L, Williams AJ, Frank J. How has child growth around adiposity rebound altered in Scotland since 1990 and what are the risk factors for weight gain using the Growing Up in Scotland birth cohort 1? BMC Public Health. 2016;16:1081. 